\title{
Distribution of Selected Cardiovascular Disease Risk Factors among Hemodialysis Patients: A Cross-Sectional Study, Cameroon
}

\author{
*Ngoufack, T.J.O. ${ }^{1,2}$, Tamanji, M.T. ${ }^{3,4}$, Mbouemboue, O.P. ${ }^{1,2}$
}

\begin{abstract}
Objective: To determine the distribution of conventional cardiovascular disease risk factors in hemodialyzed patients in a novel Cameroonian regional hemodialysis center.

Methods: This was cross-sectional study carried out at the hemodialysis center of the Garoua Regional Hospital during the period April to August 2014. Sociodemographic, clinical, anthropometric and biochemical data were assessed.

Results: Our sample population constituted 35 patients with stage V chronic kidney disease (CKD) undergoing hemodialysis. Among them, $74.3 \%$ were physically inactive while $22.9 \%$ and $2.9 \%$ presented with alcohol and tobacco consumption, respectively. The prevalence of hypertension, diabetes, dyslipidemias, overweight and obesity were estimated at $91.4 \%, 22.9 \%, 85.7 \%, 25.7 \%$ and $14.8 \%$, respectively. There was a significant difference between men and women concerning the mean values of diastolic blood pressure $(\mathrm{p}=0.036)$ and HDL cholesterol $(\mathrm{p}=0.024)$. Moreover, the mean systolic $(\mathrm{P}=$ $0.028)$ and diastolic $(\mathrm{P}=0.005)$ blood pressures were significantly highest in patients with less than a year of hemodialysis.
\end{abstract}

Conclusion: Our findings suggest that dyslipidemias and other cardiovascular disease risk factors frequently occur in hemodialyzed patients in our setting.

Keys words: Cardiovascular Diseases, Chronic Kidney Disease, Renal Dialysis, Risk Factors

\author{
*Corresponding Author \\ Ngoufack, T.J.O. \\ http://orcid.org/0000-000 \\ Email:ngoufacktsougmo@yahoo.fr
}

\footnotetext{
${ }^{1}$ Department of Biomedical Sciences, Faculty of Science, University of Ngaoundere, Ngaoundere, Cameroon ${ }^{2}$ General Medicine Service, Ngaoundere Regional Hospital, Ngaoundere, Ngaoundere, Cameroon ${ }^{3}$ linical Laboratory Service, Ngaoundere Regional Hospital, Ngaoundere, Ngaoundere, Cameroon ${ }^{4}$ Faculty of Science, University of Buea, Buea, Cameroon
} 


\title{
Distribution de quelques facteurs de risque cardiovasculaires chez des patients en hémodialyse : les résultats d'une étude transversale réalisée au Cameroun
}

\author{
*Ngoufack, T.J.O. ${ }^{1,2}$, Tamanji, M.T., ${ }^{3,4}$ Mbouemboue, O.P. ${ }^{1,2}$
}

\begin{abstract}
Résumé
Objectif: Déterminer la fréquence des facteurs de risque traditionnels des maladies cardiovasculaires chez des patients souffrant d'insuffisance rénale terminale dans un nouveau centre d'hémodialyse camerounais.
\end{abstract}

Méthode: Une étude transversale a été conduite au Centre Régional d'Hémodialyse de Garoua d'Avril à Aout 2015. Les données sociodémographiques, anthropométriques, cliniques et biologiques des patients étaient analysées.

Résultats: l'échantillon d'étude comptait 35 patients sous hémodialyse. Parmi eux, 74,3\% étaient sédentaires, $22,9 \%$ consommaient des boissons alcoolisées et 2,9\% étaient des fumeurs. Les prévalences de l'hypertension artérielle, du diabète, des dyslipidémies, du surpoids et de l'obésité étaient respectivement de $91,4 \%, 22,9 \%, 85,7 \%, 25,7 \%$ and $14,8 \%$. La pression artérielle diastolique moyenne des femmes était plus élevée que celle des hommes $(\mathrm{p}=0.036)$. Le HDL cholestérol moyen des femmes était plus élevée que celui des hommes $(\mathrm{p}=0.024)$. Les patients sous hémodialyse depuis moins un an avaient une pression artérielle supérieure à celle des autres.

Conclusion: nos résultats ont montré que les dyslipidémies et les autres facteurs de risque cardiovasculaires sont fréquents chez les patients en hémodialyse dans notre contexte.

Mots clés: Maladies cardiovasculaires, insuffisance rénale terminale, Néphropathie chronique, hémodialyse, Facteur de risqué.

\footnotetext{
*Auteur principal :

Ngoufack. T.J.O.

http://orcid.org/0000-000

Email:ngoufacktsougmo@yahoo.fr
}

\footnotetext{
${ }^{1}$ Department of Biomedical Sciences, Faculty of Science, University of Ngaoundere, Ngaoundere, Cameroon ${ }^{2}$ General Medicine Service, Ngaoundere Regional Hospital, Ngaoundere, Ngaoundere, Cameroon ${ }^{3}$ linical Laboratory Service, Ngaoundere Regional Hospital, Ngaoundere, Ngaoundere, Cameroon ${ }^{4}$ Faculty of Science, University of Buea, Buea, Cameroon
} 


\section{INTRODUCTION}

It is well established that persons suffering from end stage renal disease are at high risk of morbidity and mortality due to cardiovascular diseases (1). This is probably related to the high prevalence of cardiovascular risk factors because several studies indicate that traditional cardiovascular disease risk factors are more frequent in patients with chronic kidney disease (CKD) at dialysis and pre-dialysis stages (2). According to the results of the CHOICE Study in which 1041 dialysis patients were recruited from 19 states in the United States of America, participants had a high prevalence of diabetes (54\%), hypertension (96\%), low physical activity (80\%), hypertriglyceridemia (36\%), and low HDL cholesterol (33\%) (3). More recently, the ANSWER study shown that $86 \%$ of a Spanish incident haemodialysis population had hypertension, $43 \%$ had dyslipidaemia and $44 \%$ had a history of cardiovascular disease (4).

The exact place of these risk factors in ESRD in our environment remains insufficiently known. Previous observations have focus on the lack of renal registries and reliable statistics about the prevalence of CKD in the majority of African countries $(5,6)$. However, it has been shown that hypertension is the cause of ESRD in $21 \%$ of patients on renal replacement therapy in South Africa (5). Moreover the prevalence of diabetic nephropathy is estimated to be $14 \%-16 \%$ in South Africa, $23.8 \%$ in Zambia, 12.4\% in Egypt, $9 \%$ in Sudan, and $6.1 \%$ in Ethiopia (7). In Cameroon, new operational haemodialysis centres have been created throughout the national territory, in order to limit deaths from CKD. In this context assessing cardiovascular risk factors in patients undergoing haemodialysis may play a vital role in the development of preventive strategies of renal and cardiovascular complications in patients with CKD.

The aim of this study was to determine the place of conventional cardiovascular disease risk factors in patients with renal failure under medical follow-up in a Cameroon regional haemodialysis centre.

\section{MATERIALS AND METHODS}

Study design, population and selection criteria

This was a cross-sectional study conducted in the haemodialysis centre of the Garoua Regional Hospital spanning a four-month period (15 April - 14 August 2015). The town of Garoua represents the administrative capital of the North region of Cameroon, having a population 2,311,179 inhabitants and a surface area of $66,090 \mathrm{~km}^{2}$, constituting $10.9 \%$ of the national population and $14.2 \%$ of the nation's surface area respectively (8). Since there were few patients undergoing haemodialysis in the centre, all of those suffering from ESRD (stage $\mathrm{V}$ $\mathrm{CKD}, \mathrm{GFR}<15 \mathrm{ml} / \mathrm{min} / 1.73 \mathrm{~m}^{2}$ ), who have been on haemodialysis at for at least a month and, who gave their consent to participate, were consecutively included in the study. Patients suffering from acute kidney failure, those who had not commenced haemodialysis and those who did not consented to participate were excluded.

\section{Study variables and data collection procedure}

Sociodemographic, clinical and anthropometric data were recorded during medical visits with the help of a structured questionnaire. These were Gender, age, alcohol consumption, smoking, physical inactivity, systolic blood pressure, diastolic blood pressure, height weight and body mass index. Biological data were fasting blood glucose, total cholesterol, high density lipoprotein (HDL) cholesterol, low density lipoprotein (LDL) cholesterol, triglycerides, total cholesterol-to-HDLc ratio.

\section{Measurement of anthropometric parameters}

Weight measurements were done using a mechanical weighing balance (mark: SECA), calibrated at the beginning of each day and ensuring that the scale was on a flat and stable surface. The participants were barefooted, lightly dressed and the weight was measured to the nearest 100 grams (9). Participants' heights were measured using a graduated flexible nonextensible ribbon tape (Gulick measuring tape $\mathrm{C}$ ) provided with a spring enabling the adjustment of the tension applied during measurement and having a measurement precision of $0.1 \mathrm{~cm}$. The participants had to stand barefoot, without any headwear, with heels assembled and the tips of the feet slightly apart. The reading was performed with the help of an incorporated sliding track system. Body mass index was calculated using the Quetelet formula, stated as weight $(\mathrm{kg})$ divided by the square of height $(\mathrm{m})$ and classified as less than $18.5 \mathrm{~kg} / \mathrm{m}^{2}$ (underweight), 18.5-24.9 $\mathrm{kg} / \mathrm{m}^{2}$ (normal weight), $25.0-29.9 \mathrm{~kg} / \mathrm{m}^{2}$ (overweight), and $30.0 \mathrm{~kg} / \mathrm{m}^{2}$ or more (obesity) (9).

\section{Measurement of clinical and biological parameters}

Resting blood pressure measurements were performed using an electronic blood 
pressure meter $\left(\right.$ Omron ${ }^{\circledR}, \mathrm{BP} 785$, USA) calibrated against a manual sphygmomanometer daily and following the JNC 7 recommendations (10). Fasting blood glucose was measured using a glucometer (One touch ultra 2, Lifescan Inc. Johnson \& Johnson Company, Milpitas, CA 95035 USA). The rest of the biological measurements were done at the Centre Pasteur Laboratory, Garoua annex, Cameroon. Serum total cholesterol and triglyceride levels were determined by spectrophotometry following the CHOD-PAP and GPO-PAP methods respectively. HDL cholesterol levels were determined in supernatant solutions following precipitation of HDL lipoproteins. Results were interpreted and analyzed following manufacturer's normal ranges thus; Total cholesterol: $<5.73 \mathrm{mmol} / \mathrm{l}$ : Triglycerides: $<1.46 \mathrm{mmol} / 1$, HDL cholesterol: $0.9-2.1 \mathrm{mmol} / 1$. LDL cholesterol calculated following the Friedwald's equation $[\mathrm{LDL}(\mathrm{mmol} / \mathrm{l})=\mathrm{TC}-\mathrm{HDL}-$ TG/2.2] for all triglyceride measurements less than $4 \mathrm{mmol} / 1$ (11), and results classified as low risk for values $<3.69 \mathrm{mmol} / \mathrm{l}$. Total cholesterolto-HDLc ratio was report as low risk for atherogenesis for values $\leq 4.85$. Dyslipidemias were defined using manufacturer's normal ranges as total cholesterol level $\geq 5.73 \mathrm{mmol} / \mathrm{l}$, triglyceride level $\geq 1.46 \mathrm{mmol} / \mathrm{l}, \mathrm{HDL}$ cholesterol level $\leq 0.9 \mathrm{mmol} / 1$ or LDL cholesterol level $>4.85 \mathrm{mmol} / 1$.

\section{Statistical analyses}

Data were recorded using the Census and Survey Processing System (CSPro) 4.1 software and later imported into the Statistical Package for the Social Sciences (SPSS) 20.0 software for statistical analyses. Results for qualitative or categorical variables were presented as percentages and those of continuous quantitative variables as means $\pm \mathrm{SD}$, all in the same tables. Comparisons of frequencies and means were done using the Pearson's Chi square and the ANOVA tests respectively. P-values equals or less than 0.05 were consider as statistically significant.

Ethical considerations: This study obtained approval from the Local Ethical Committee (Ref: 1215/L/RC/RN/DSP/HR/GRA/ CLE) and the administrative authority of the Garoua Regional Hospital. Participants were well informed on the merits and demerits of this study after which those interested provided a written consent to participate.

\section{RESULTS}

A total of 35 patients undergoing haemodialysis participated in the study. Among them, there were 25 men and 10 women. Following their age groups, 18 of them were 20 49 years old and 17 were 50 years old or above. The prevalence of hypertension, diabetes, dyslipidaemia, overweight and obesity were estimated at $94.4 \%, 22.9 \%, 85.7 \%, 25.7 \%$, $14.8 \%$, respectively. There was no significant difference between men and women concerning cardiovascular diseases risk factors, except for the mean values of diastolic blood pressure $(\mathrm{P}=$ $0.036)$ and HDL cholesterol $(\mathrm{P}=0.024)$ (Table 1).

Following categorization of study participants by age group, we observed that patients aged 50 years and above were significantly more sedentary compared to those younger $(\mathrm{P}=0.011)$. Also, the mean fasting blood glucose $(\mathrm{P}=0.020)$ and triglyceride $(\mathrm{P}=0.030)$ levels were higher in participants aged 50 years and above. All other studied variables were equivalently distributed between the two age groups (Table 2). We went further to categorize patients based on their duration on dialysis, where we observed that the mean systolic $(\mathrm{P}=$ $0.028)$ and diastolic $(P=0.005)$ blood pressures were significantly highest in patients with less than a year of haemodialysis (Table 3 ).

\section{DISCUSSION}

According to recent data, $\mathrm{CKD}$ is on the rise worldwide and affects at least one adult out of ten (12), with the sub-Saharan population being particularly vulnerable. Our study permits the provision of additional information on the place of conventional cardiovascular disease risk factors in a population of patients undergoing haemodialysis in a regional haemodialysis centre in Cameroon. The results highlighted high frequencies of hypertension, diabetes, dyslipidaemias and sedentary.

\section{Sedentary Lifestyle}

Muscle weakness and excessive fatigue constitute some of the complications of concern in patients with CKD, especially among those on hemodialysis. They carry out reduced physical activity which could pose serious cardiac implications such as coronary pathologies, demonstrating the association of physically active lifestyle with a reduction in the occurrence of cardiovascular complications during hospital stay, which has been previously reported by Jorge et al in a Brazilian study (13). Our results indicated that $74.8 \%$ of patients were sedentary 
with a higher occurrence among males (84\%). This is close to the $73.1 \%$ reported by Burmeister et al. in a study carried out in patients undergoing haemodialysis (14). Among patients aged 50 years and above, $94.1 \%$ practiced no physical activity compared to $55.6 \%$ in those $20-49$ years old. We also noted a significant association between age and physical inactivity $(\mathrm{P}=0.011)$. Our results corroborate with those of Karimi et al (15) who reported a correlation of advance age with the decrease of physical activity. Thus, advanced age may limit physical activity due to aging skeletal system resulting in functionally decreased muscle and bone strength, and aging of the articular cartilage resulting in joint pain during movement (16).

\section{Tobacco Consumption}

Tobacco produces acute hemodynamic alterations such as increased heart rate, coronary vascular resistance, myocardial contractility and myocardial oxygen demand (17). According to Muntner et al., tobacco consumption is associated with increased risk of coronary heart disease in patients suffering from CKD (18). Only $2.9 \%$ of our study participants were smokers, results which are close to the $5 \%$ of Hou et al. in a Chinese multicentric study (19), but far below the $11 \%$ reported by Perez-Garcia et al. in Spain (4). Persons at any stage of CKD require a good state of health and hygiene thus the low rate of smoking observed in our study could be explained by the possibility that a majority of these hemodialysis patients respected the recommended lifestyle changes.

\section{Hypertension}

The interaction between hypertension and CKD is complex. On one hand hypertension is a potential cause of renal failure where it is responsible for about $30 \%$ of cases of ESRD, and on the other, a common consequence of chronic renal failure. In our study, the majority of patients $(91.4 \%)$ were hypertensive, results which are in line with the findings of the CHOICE study in which $96 \%$ of patients with renal failure were hypertensive (3). Literature holds that the prevalence of hypertension among patients with end stage renal disease varies between $80 \%$ and $90 \%(14,20)$. We recorded mean systolic and diastolic BP of $148.28 \pm 14.92 \mathrm{mmHg}$ and $86.68 \pm 12.28 \mathrm{mmHg}$ respectively in patients. These values are similar to those of the CHOICE (3) and the CORDIAL (14) studies, but higher than those reported by Hou et al (19). In accordance with the CORDIAL study (14), we failed to demonstrate associations between hypertension and gender, participants' age, and duration of dialysis, although the mean diastolic BP was significantly higher in females compared to males, being identical to the reports of Burmeister et al. (14), and the means of both systolic and diastolic BP were observed to be significantly higher in patients with less than a year of haemodialysis compared to patients with a longer duration of dialysis. This may be the result of the fact that hypertension is both a cause and a consequence of chronic renal failure leading to a high prevalence of this risk factor in haemodialysis patients, and also, owing to the fact that frequent haemodialysis reduces blood pressure (21). The fact that blood pressure is difficult to control in the initial phases of haemodialysis and that dialysis causes a sudden rise in blood pressure may be a possible contributing factor (21).

\section{Diabetes}

Resistance to insulin is a characteristic of type 2 diabetes and chronic uremia (22). Insulin resistance and decreased insulin clearance lead to fluctuations in plasma glucose making glycemic control difficult in diabetic patients with ESRD (23). The prevalence of diabetes was $22.8 \%$ in this study and all diabetic participants were of the type 2 category. This rate is close to the $21.6 \%$ reported by Kabbali et al. in a Moroccan population of patients undergoing haemodialysis (24). Conversely, El Farouki et al. reported a $41.5 \%$ prevalence in another Moroccan study (25), which is higher than the one reported in the present study. Since diabetes is a frequent cause of CKD, the variation of its prevalence among patients in haemodialysis may reflect the same variation in the local population. However, patients undergoing haemodialysis in our study recorded a mean fasting blood glucose level of $1.00 \pm 0.29 \mathrm{~g} / \mathrm{l}$, similar to that reported by Sobngwi et al. in another Cameroonian study (26).

\section{Obesity}

In this study, $51.5 \%$ of patients on dialysis had a normal BMI, while $25.7 \%$, and $14.8 \%$ were overweight and obese respectively. This is in line with the CORDIAL study which recorded $52.2 \%, 29.4 \%$ and $12.4 \%$ normal, overweight, and obese respectively (14).

\section{Dyslipidemias \\ We observed a $85.7 \%$ prevalence of dyslipidemias among patients undergoing}


haemodialysis, results which are in line with the $80 \%$ and $84.7 \%$ reported in a Moroccan (27) and the CORDIAL (14) studies respectively. These variations could be due to the non-systematic prescription of hypolipemic drugs to patients undergoing haemodialysis diagnosed with dyslipidemias in our setting. Otherwise, previous literature puts dyslipidemias among the commonest cardiovascular disease risk factors associated with CKD (28). The mean total cholesterol level in our study group was $3.71 \pm$ $1.28 \mathrm{mmol} / \mathrm{l}$, which was lower compared to the $4.33 \mathrm{mmol} / \mathrm{l}$ reported in a Moroccan (27) and the CORDIAL studies (14).

Serum triglyceride mean level was $1.60 \pm 0.93 \mathrm{mmol} / 1$, indicating a net hypertriglyceridemia in study patients. This level is similar to the $1.49 \mathrm{mmol} / 1$ reported by Idrissi et al. (27), although higher than the one reported in the ANSWER study (4). According to Li and Wang, about one third of haemodialysis patients have hypertriglyceridemia with the principal cause being a lipoprotein lipase deficiency (29). Also, we noted that the mean triglyceride level was significantly higher in patients 50 years and above compared to those younger $(\mathrm{P}=0.03)$. According to several authors, advanced age is a determinant for dyslipidemias in the general population (30).

In addition, male patients presented significantly low mean HDL levels compared to their female counterparts $(\mathrm{P}=0.024)$. It has been suggested that males are more at risk of developing dyslipidemias compared to females of the same age (29).

Limitations: The cost of haemodialysis is the primary limiting factor for patients with ESRD in our context, thus only persons who could afford were generally admitted in this service. Also, there is a low level of awareness on end stage renal disease in the general population resulting in prompt death prior to diagnosis in a majority of cases in this resource deficient setting. Moreover, the study site was a newly installed haemodialysis centre which is yet to make a progressive impact on the general population. The 35 patients represent the total of population of patients admitted at the centre during study period, thus our sample size equals the total population of patients with end stage renal disease admitted at the centre within the study period.

\section{CONCLUSION}

Despite this reduced sample size, our study shows that cardiovascular diseases risk factors frequently occur in dialysis patients with end stage renal disease. Among these classical cardiovascular disease risk factors studied, hypertension is the most encountered risk factor, followed by lipid disorders and physical inactivity.

Acknowledgments: The authors appreciate the collaboration of the administrative and medical staff of the Garoua Regional Hospital and Haemodialysis centre for their support with data collection.

Conflict of interests: The authors declare no conflict of interests regarding the publication of this paper.

\section{REFERENCES}

1. Rucker D and Tonelli M. Cardiovascular risk and management in chronic kidney failure. Nat Rev Nephrol. 2009; 5 (5): 287-96.

2. Matsushita K, Van Der Velde M, Astor BC et al. Association of estimated glomerular filtration rate and albuminuria with all-cause and cardiovascular mortality in general population cohorts: a collaborative meta-analysis. Lancet. 2010; 375 (9731): 2073-81.

3. Longenecker JC, Coresh J, Powe NR et al. Traditional Cardiovascular Disease Risk Factors in Dialysis Patients Compared with the General Population: The CHOICE Study. $J$ Am Soc Nephrol. 2002; 13 (7): 1918-27.

4. Pérez-García R, Martín-Malo A, Fort $\mathrm{J}$ et al. Baseline characteristics of an incident hemodialysis population in Spain: results from ANSWER - a multicenter, prospective, observational cohort study. Nephrol Dial Transplant. 2009; 24 (2): 578-88.

5. Naicker S. End-stage renal disease in SubSaharan Africa. Kidney International. 2013; 3 (Supplements): 161-163.

6. Stanifer JW, Jing B, Tolan $\mathrm{S}$ et al. The epidemiology of chronic kidney disease in subSaharan Africa: a systematic review and metaanalysis. Lancet Global Health. 2014; 2: e174181.

7. Naicker S. End-stage renal disease in sub-Saharan Africa. Ethn Dis Spring. 2009; 19(1 Suppl 1):S113. PMID: 19484867.

8. Institut National de la Statistique, Annuaire statistique du Cameroun : Recueil des séries d'informations statistiques sur les activités économiques, sociales, politiques et culturelles du pays jusqu'en 2013, Institut National de la Statistique, Yaoundé, Cameroun, Edition 2013. 2013;30-31.

9. World Health Organization, STEPS: The WHO STEPwise approach to noncommunicable disease risk factor surveillance, World Health 
Organization. Geneva, Switzerland. 2008.

10. Chobanian AV, Bakris GL, Black HR et al. The Seventh Report of the Joint National Committee on Prevention, Detection, Evaluation, and Treatment of High Blood Pressure: the JNC 7 report. JAMA. 2003; 289: 2560-72.

11. Friedewald WT, Levy RI and Fredrickson DS. Estimation of the concentration of low-density lipoprotein cholesterol in Plasma, without use of the preparative ultracentrifuge. Clinical chemistry.1972; 18 (6): 499-502.

12. Jha VG, Garcia-Garcia, Iseki $\mathrm{K}$ et al. Chronic kidney disease: global dimension and perspectives. Lancet. 2013; 382 (9888): 260-272.

13. Jorge JG, Santos MAA, Filho JASB et al. Level of Physical Activity and In-Hospital Course of Patients with Acute Coronary Syndrome. Arquivos Brasileiros De Cardiologia. 2016; 106 (1): 33-40.

14. Burmeister JE, Mosmann CB, Costa VB et al. Prevalence of Cardiovascular Risk Factors in Hemodialysis Patients - The CORDIAL Study. Arquivos Brasileiros De Cardiologia. 2014 ; 102 (5) : 473-80.

15. Karimi I, Ben abdellah N, Bentata Y, Yacoubi H and Haddiya I. Evaluation du niveau d'activité physique dans un service Marocain d'hémodialyse chronique. Pan African Medical Journal. 2013; 15(79).

16. Lee IM, Djousse L, Sesso HD, Wang L and Buring JE. Physical activity and weight gain prevention. JAMA. 2010; 303 (12): 1173-9.

17. Wambua MC and Jamal I. Tobacco use and the cardiovascular disease epidemic in developing countries: prevention opportunity. DMSJ. 2012; 19(1): 17-21.

18. Muntner P, He J, Astor BC, Folsom AR and Coresh J. Traditional and Nontraditional Risk Factors Predict Coronary Heart Disease in Chronic Kidney Disease: Results from the Atherosclerosis Risk in Communities Study. $\mathrm{J} \mathrm{Am}$ Soc Nephrol. 2005; 16(2): 529-38.

19. Hou F, Jiang J, Chen J et al. China collaborative study on dialysis: a multi-centers cohort study on cardiovascular diseases in patients on maintenance dialysis. BMC Nephrol. 2012; 13 (94).
20. Agarwal R, Nissenson AR, Batlle $D$ et al. Prevalence, treatment, and control of hypertension in chronic hemodialysis patients in the United States. Am J Med. 2003; 115 (4): 291297.

21. Kotanko P, Garg AX, Depner T et al. Effects of frequent hemodialysis on blood pressure: Results from the randomized frequent hemodialysis network trials. Hemodial Int. 2015; 19 (3): 386401.

22. Pham H, Utzschneider KM and De Boer IH. Measurement of insulin resistance in chronic kidney failure. Curr Opin Nephrol Hypertens. 2011;20 (6): 640-6.

23. Liao MT, Sung CC, Hung $\mathrm{KC}$ et al. Insulin Resistance in Patients with Chronic Kidney Disease. J Biomed Biotechnol. 2012; 2012, ID. 91369.

24. Kabbali N, Mikou S, El Pardiya NT et al. Profil des diabétiques en hémodialyse chronique: étude multicentrique au Maroc. Pan Afr Med J. 2014; 2 (17): 125

25. El Farouki MR, Bahadi AA, Hamzi MA et al. Profil des insuffisants rénaux chroniques diabétiques à l'initiation de l'hémodialyse au service de néphrologie et dialyse de l'hôpital militaire de Rabat, Maroc. Pan Afr Med J. 2013; $15(1): 124$

26. Sobngwi E, Enoru S, Ashuntantang G et al. Dayto-Day Variation of Insulin Requirements of Patients with Type 2 Diabetes and End-Stage Renal Disease Undergoing Maintenance Hemodialysis. Diabetes Care. 2010 ; 33 (7) : 1409-1412.

27. Idrissi SE, Dami A, Bouhsain S et al. Profil lipidique dans l'insuffisance rénale chronique au stade d'hémodialyse: étude marocaine. Sante. 2011; 21 (1):27-31.

28. Batta FZ, Houssaini TS, Sekkouri KA et al. Hemodialysis-associated dyslipidemia: effect of virgin argane oil consumption. JIRMEPS. 2016; 9 (3): $139-45$

29. $\mathrm{Li} \mathrm{H}$, Wang $\mathrm{S}$. Cardiovascular Disease in Hemodialysis Patients. In Hemodialysis, Edited by Hiromichi Suzuki. 2013; DOI: 10.5772/45929.

30. Sun GZ, Li Z, Guoet L al. High prevalence of dyslipidemia and associated risk factors among rural Chinese adults. Lipids Health Dis. 2014; 13 (189). 
Table 1: Distribution of cardiovascular disease risk factors by gender

\begin{tabular}{|c|c|c|c|c|c|c|c|}
\hline \multirow{2}{*}{ Variables } & \multicolumn{2}{|c|}{ Men } & \multicolumn{2}{|c|}{ Women } & \multicolumn{2}{|c|}{ Total } & \multirow[t]{2}{*}{ p-value } \\
\hline & $\mathbf{N}$ & $\%$ & $\mathbf{N}$ & $\%$ & $\mathbf{N}$ & $\%$ & \\
\hline Overall & 25 & 100 & 10 & 100 & 35 & 100 & \\
\hline \multicolumn{8}{|l|}{ Physical inactivity } \\
\hline No & 4 & 16.0 & 5 & 50.0 & 9 & 25.7 & \multirow{2}{*}{0.053} \\
\hline Yes & 21 & 84.0 & 5 & 50.0 & 26 & 74.3 & \\
\hline \multicolumn{8}{|l|}{ Alcohol consumption } \\
\hline No & 17 & 68.0 & 10 & 100 & 27 & 77.1 & \multirow{2}{*}{0.064} \\
\hline Yes & 8 & 32.0 & 0 & 0 & 8 & 22.9 & \\
\hline \multicolumn{8}{|l|}{ Tobacco consumption } \\
\hline No & 24 & 96.0 & 10 & 100 & 34 & 97.1 & \multirow{2}{*}{0.714} \\
\hline Yes & 1 & 4.0 & 0 & 0 & 1 & 2.9 & \\
\hline \multicolumn{8}{|l|}{ Hypertension } \\
\hline No & 3 & 12.0 & 0 & 0 & 3 & 8.6 & \multirow{2}{*}{0.351} \\
\hline Yes & 22 & 88.0 & 10 & 100 & 32 & 91.4 & \\
\hline \multicolumn{8}{|l|}{ Diabetes } \\
\hline No & 20 & 80.0 & 7 & 70.0 & 27 & 77.1 & \multirow{2}{*}{0.330} \\
\hline Yes & 5 & 20.0 & 3 & 30.0 & 8 & 22.9 & \\
\hline \multicolumn{8}{|l|}{ Dyslipidemia } \\
\hline No & 3 & 12.0 & 2 & 20.0 & 5 & 14.3 & \multirow{2}{*}{0.045} \\
\hline Yes & 22 & 88.0 & 8 & 80.0 & 30 & 85.7 & \\
\hline \multicolumn{8}{|l|}{ Body Mass Index } \\
\hline Underweight & 2 & 8.0 & 1 & 10.0 & 3 & 8.5 & \multirow{4}{*}{0.365} \\
\hline Normal body mass index & 12 & 48.0 & 4 & 40.0 & 18 & 51.4 & \\
\hline Overweight & 7 & 28.0 & 2 & 20.0 & 9 & 25.7 & \\
\hline Obesity & 2 & 8.0 & 3 & 30.0 & 5 & 14.8 & \\
\hline \multicolumn{8}{|l|}{ Mean values $($ Mean $\pm \mathbf{S D})$} \\
\hline Systolic blood pressure (mmHg) & \multirow{2}{*}{\multicolumn{2}{|c|}{$\begin{array}{l}148.76 \pm 12.51 \\
83.96 \pm 12.41\end{array}$}} & \multicolumn{2}{|c|}{$147.1 \pm 20.53$} & \multicolumn{2}{|c|}{$148.28 \pm 14.92$} & 0.771 \\
\hline Diastolic blood pressure $(\mathrm{mmHg})$ & & & \multirow{2}{*}{\multicolumn{2}{|c|}{$24 \pm 3.76$}} & & $8 \pm 12.28$ & $0.036 *$ \\
\hline Body mass index $\left(\mathrm{kg} / \mathrm{m}^{2}\right)$ & \multicolumn{2}{|c|}{$22.13 \pm 3.74$} & & & \multicolumn{2}{|c|}{$23.06 \pm 3.75$} & 0.069 \\
\hline Fasting Blood Glucose (g/L) & \multicolumn{2}{|c|}{$0.97 \pm 0.26$} & 1.07 & $=0.38$ & 1.0 & \pm 0.29 & 0.368 \\
\hline Total Cholesterol (mmol/L) & 3.6 & \pm 1.43 & 3.90 & $=0.83$ & 3.7 & \pm 1.28 & 0.585 \\
\hline Triglyceride (mmol/L) & 1.4 & \pm 0.94 & 1.88 & $=0.83$ & 1.6 & \pm 0.93 & 0.258 \\
\hline HDL Cholesterol $(\mathrm{mmol} / \mathrm{L})$ & 0.7 & \pm 0.29 & 1.21 & $=0.79$ & 0.9 & \pm 0.51 & $0.024 *$ \\
\hline LDL Cholesterol (mmol/L) & 2.3 & \pm 0.93 & 2.01 & 0.81 & 2.2 & \pm 0.90 & 0.386 \\
\hline Total Cholesterol-to-HDLc ratio & 5.0 & \pm 2.17 & 4.53 & $=1.50$ & 4.8 & \pm 2.00 & 0.501 \\
\hline
\end{tabular}

$* \mathrm{P}<0.05$. HDL: high density lipoprotein. LDL: low density lipoprotein. 
Table 2: Distribution of cardiovascular disease risk factors by age group

\begin{tabular}{|c|c|c|c|c|c|}
\hline \multirow{2}{*}{ Variables } & \multicolumn{2}{|c|}{20 to 49 years } & \multicolumn{2}{|c|}{$\geq 50$ years } & \multirow[t]{2}{*}{ p-value } \\
\hline & $\mathbf{N}$ & $\%$ & $\mathbf{N}$ & $\%$ & \\
\hline Overall & 18 & 100 & 17 & 100 & \\
\hline \multicolumn{6}{|l|}{ Physical Inactivity } \\
\hline No & 8 & 44.4 & 1 & 5.9 & \multirow[t]{2}{*}{$0.011 *$} \\
\hline Yes & 10 & 55.6 & 16 & 94.1 & \\
\hline \multicolumn{6}{|l|}{ Alcohol consumption } \\
\hline No & 14 & 77.8 & 13 & 81.2 & \multirow[t]{2}{*}{0.571} \\
\hline Yes & 4 & 22.2 & 4 & 18.8 & \\
\hline \multicolumn{6}{|l|}{ Tobacco consumption } \\
\hline No & 17 & 94.4 & 17 & 100 & \multirow{2}{*}{0.514} \\
\hline Yes & 1 & 5.6 & 0 & 0 & \\
\hline \multicolumn{6}{|l|}{ Hypertension } \\
\hline No & 1 & 5.6 & 2 & 11.8 & \multirow[t]{2}{*}{0.478} \\
\hline Yes & 17 & 94.4 & 15 & 88.2 & \\
\hline \multicolumn{6}{|l|}{ Diabetes } \\
\hline No & 15 & 83.3 & 12 & 70.6 & \multirow[t]{2}{*}{0.199} \\
\hline Yes & 3 & 16.6 & 5 & 29.4 & \\
\hline \multicolumn{6}{|l|}{ Dyslipidemia } \\
\hline No & 2 & 11.1 & 3 & 1.8 & \multirow{2}{*}{0.457} \\
\hline Yes & 16 & 88.9 & 14 & 98.2 & \\
\hline \multicolumn{6}{|l|}{ Body Mass Index } \\
\hline Underweight & 1 & 5.6 & 2 & 11.8 & \multirow{4}{*}{0.079} \\
\hline Normal body mass index & 10 & 55.6 & 8 & 47.1 & \\
\hline Overweight & 5 & 27.8 & 4 & 23.5 & \\
\hline Obesity & 2 & 11.1 & 3 & 1.8 & \\
\hline \multicolumn{6}{|l|}{ Mean Values $($ Mean \pm SD) } \\
\hline $\begin{array}{l}\text { Systolic blood pressure } \\
(\mathrm{mmHg})\end{array}$ & \multicolumn{2}{|c|}{$149.72 \pm 14.18$} & \multicolumn{2}{|c|}{$146.76 \pm 15.96$} & 0.566 \\
\hline $\begin{array}{l}\text { Diastolic blood pressure } \\
(\mathrm{mmHg})\end{array}$ & \multicolumn{2}{|c|}{$86.86 \pm 13.82$} & \multicolumn{2}{|c|}{$86.68 \pm 10.83$} & 0.943 \\
\hline Body mass index $\left(\mathrm{kg} / \mathrm{m}^{2}\right)$ & \multicolumn{2}{|c|}{$21.15 \pm 3.24$} & \multicolumn{2}{|c|}{$23.79 \pm 3.55$} & 0.579 \\
\hline $\begin{array}{l}\text { Fasting Blood Glucose } \\
(\mathrm{g} / \mathrm{L})\end{array}$ & \multicolumn{2}{|c|}{$0.89 \pm 0.25$} & \multicolumn{2}{|c|}{$1.12 \pm 0.3$} & $0.020 *$ \\
\hline Total Cholesterol $(\mathrm{mmol} / \mathrm{L})$ & \multicolumn{2}{|c|}{$3.61 \pm 1.07$} & 3.81 & 1.51 & 0.664 \\
\hline Triglyceride $(\mathrm{mmol} / \mathrm{L})$ & 1.27 & 0.68 & 1.94 & 1.04 & $0.030 *$ \\
\hline HDL Cholesterol (mmol/L) & 0.91 & 0.46 & 0.91 & 0.58 & 0.989 \\
\hline LDL Cholesterol (mmol/L) & 1.95 & 0.59 & 2.5 & 1.09 & 0.071 \\
\hline $\begin{array}{l}\text { Total Cholesterol-to-HDLc } \\
\text { ratio }\end{array}$ & 4.48 & 1.73 & 5.33 & 2.21 & 0.216 \\
\hline
\end{tabular}

$* \mathrm{P}<0.05$. HDL: high density lipoprotein. LDL: low density lipoprotein. 
Table 3: Distribution of Cardiovascular Disease Risk Factors by duration of dialysis

\begin{tabular}{|c|c|c|c|c|c|c|c|}
\hline \multirow{2}{*}{ Variables } & \multicolumn{2}{|c|}{ Less than 1 year } & \multicolumn{2}{|c|}{1 to 5 years } & \multicolumn{2}{|c|}{5 to 10 years } & \multirow[t]{2}{*}{ p-value } \\
\hline & $\mathbf{N}$ & $\%$ & $\mathbf{N}$ & $\%$ & $\mathbf{N}$ & $\%$ & \\
\hline Overall & 12 & 100 & 16 & 100 & 7 & 100 & \\
\hline \multicolumn{8}{|l|}{ Physical Inactivity } \\
\hline No & 5 & 41.7 & 1 & 6.3 & 3 & 42.9 & \multirow{2}{*}{0.126} \\
\hline Yes & 7 & 58.3 & 15 & 93.8 & 4 & 57.1 & \\
\hline \multicolumn{8}{|l|}{ Alcohol consumption } \\
\hline No & 11 & 91.7 & 14 & 87.5 & 2 & 28.6 & \multirow{2}{*}{$0.001 *$} \\
\hline Yes & 1 & 8.3 & 2 & 12.5 & 5 & 71.4 & \\
\hline \multicolumn{8}{|l|}{ Tobacco consumption } \\
\hline No & 12 & 100 & 15 & 93.8 & 7 & 100 & \multirow{2}{*}{0.615} \\
\hline Yes & 0 & 0 & 1 & 6.3 & 0 & 0 & \\
\hline \multicolumn{8}{|l|}{ Hypertension } \\
\hline No & 0 & 0 & 3 & 18.8 & 0 & 0 & \multirow{2}{*}{0.212} \\
\hline Yes & 12 & 100 & 13 & 81.3 & 7 & 100 & \\
\hline \multicolumn{8}{|l|}{ Diabetes } \\
\hline No & 9 & 75 & 13 & 81.2 & 5 & 71.4 & \multirow{2}{*}{0.443} \\
\hline Yes & 3 & 25 & 3 & 18.8 & 2 & 28.6 & \\
\hline \multicolumn{8}{|l|}{ Dyslipidemia } \\
\hline No & 4 & 33.3 & 1 & 6.2 & 0 & 0 & \multirow{2}{*}{0.512} \\
\hline Yes & 8 & 66.7 & 15 & 93.8 & 7 & 100 & \\
\hline \multicolumn{8}{|l|}{ Body Mass Index } \\
\hline Underweight & 0 & 0 & 2 & 12.5 & 1 & 14.3 & \multirow{4}{*}{0.096} \\
\hline Normal body mass index & 7 & 58.3 & 8 & 50.0 & 3 & 42.9 & \\
\hline Overweight & 4 & 33.3 & 3 & 18.8 & 2 & 28.6 & \\
\hline Obesity & 1 & 8.3 & 3 & 18.8 & 1 & 14.3 & \\
\hline \multicolumn{8}{|l|}{ Mean Values $($ Mean \pm SD) } \\
\hline Systolic blood pressure (mmHg) & \multicolumn{2}{|c|}{$157.33 \pm 9.27$} & \multicolumn{2}{|c|}{$143.00 \pm 6.65$} & \multicolumn{2}{|c|}{$145.6 \pm 4.92$} & $0.028 *$ \\
\hline Diastolic blood pressure (mmHg) & \multicolumn{2}{|c|}{$95.33 \pm 7.57$} & \multicolumn{2}{|c|}{$81.33 \pm 12.7$} & \multicolumn{2}{|c|}{$85.2 \pm 9.09$} & $0.005 *$ \\
\hline Body mass index $\left(\mathrm{kg} / \mathrm{m}^{2}\right)$ & \multicolumn{2}{|c|}{$23.52 \pm 4.11$} & 22. & \pm 3.43 & 22 & $9 \pm 4.41$ & 0.126 \\
\hline Fasting Blood Glucose $(\mathrm{g} / \mathrm{L})$ & 1.0 & \pm 0.41 & 1.0 & \pm 0.22 & 0.8 & $3 \pm 0.17$ & 0.342 \\
\hline Total Cholesterol $(\mathrm{mmol} / \mathrm{L})$ & 4.0 & \pm 1.23 & 3.58 & \pm 1.44 & 3.4 & $1 \pm 0.8$ & 0.606 \\
\hline Triglyceride (mmol/L) & 1.6 & \pm 1.08 & 1.6 & \pm 0.97 & & $7 \pm 0.18$ & 0.845 \\
\hline HDL Cholesterol (mmol/L) & 1.0 & \pm 0.62 & 0.8 & \pm 0.48 & 0.8 & $0 \pm 0.33$ & 0.487 \\
\hline LDL Cholesterol (mmol/L) & 2.0 & \pm 0.70 & 2.35 & \pm 1.04 & 2.0 & $2 \pm 0.77$ & 0.528 \\
\hline Total Cholesterol-to-HDLc ratio & 4.4 & \pm 2.27 & 5.2 & \pm 1.87 & 4.8 & $4 \pm 1.92$ & 0.554 \\
\hline
\end{tabular}

${ }^{*} \mathrm{P}<0.05$. HDL: high density lipoprotein. LDL: low density lipoprotein. 